Pesq. Vet. Bras. 37(5):471-478, maio 2017

DOI: $10.1590 /$ S0100-736X2017000500008

\title{
Adição de antioxidantes ao sêmen de carneiros e seus efeitos após a descongelação ${ }^{1}$
}

\author{
Wildelfrancys L. Souza ${ }^{2}$, Elenice A. Moraes ${ }^{3 *}$ e Ricardo Toniolli²
}

\begin{abstract}
Souza W.L., Moraes E.A. \& Toniolli R. 2017. [Addition of antioxidants in ram semen and the effects after thawing.] Adição de antioxidantes ao sêmen de carneiros e seus efeitos após a descongelação. Pesquisa Veterinária Brasileira 37(5):471-478. Programa de Pós-Graduação em Ciências Veterinárias, Universidade Estadual do Ceará, Campus do Itaperi, Av. Dr. Silas Muguba 1700, Fortaleza, CE 60740-000, Brazil. E-mail: wilde@zootecnista.com.br

Aimed to evaluate the effect of adding antioxidants as ascorbic acid, melatonin and Trolox $\mathrm{C}$ to diluted semen of ram with oxidative stress to potenciate fertilization after cryopreservation. Ten samples collected were diluted in Tris-egg yolk to a final concentration of $200 \times 10^{6} \mathrm{sperm} / \mathrm{mL}$ and kept in a water bath at $32^{\circ} \mathrm{C}$. Antioxidants were added as follows: $100 \mu \mathrm{M}$ melatonin (MEL) $+.05 \%$ ascorbic acid (AA); $100 \mu \mathrm{M}$ of MEL $+90 \mu \mathrm{L}$ of Trolox C (TRO); $90 \mu \mathrm{L}$ of TRO $+0.05 \% \mathrm{AA}$; and $100 \mu \mathrm{M}$ of MEL0.05\% AA + 90 $\mu \mathrm{L}$ of TRO. Semen was cooled in a cold chamber at $5^{\circ} \mathrm{C}$ for two hours and packaged, sealed in $0.5 \mathrm{~mL}$ straws, packaged under liquid nitrogen vapor $\left(\mathrm{N}_{2} \mathrm{~L}\right), 8 \mathrm{~cm}$ of water depth for 15 minutes, and then immersed in $\mathrm{N}_{2} \mathrm{~L}$. Samples were assayed for motility, integrity of the plasma membrane and acrosomal membrane, mitochondrial activity, binding assay and oxidative stress spermatozoa. The variables were analyzed by ANOVA and means compared by Tukey test $(\mathrm{P}<0.05)$. Percentage of total and progressive motility was higher for sperm treated with MEL+AA+TRO (67\% and 49.89\%), MEL+AA (64.37\% and 45.61\%) and MEL+TRO (61.65\% and $41.15 \%)$ compared with the other treatments $(\mathrm{P}<0.05)$. The integrity of the plasma membrane and acrosome was higher for all semen treated with antioxidant associations compared with control $(\mathrm{P}<0.05)$. Mitochondrial activity was higher in sperm treated with MEL+AA+TRO compared all treatments $(\mathrm{P}<0.05)$. The number of sperm binding to perivitelline membrane was higher for semen treated with antioxidant associations compared with control; also sperm treated with MEL+AA+TRO demonstrated higher effect of all $(\mathrm{P}<0.05)$. No difference was observed between the treatments by oxidative stress sperm $(P>0.05)$. The addition of melatonin, ascorbic acid and Trolox $\mathrm{C}$ in diluted semen of ram improves sperm quality after thawing.
\end{abstract}

INDEX TERMS: Antioxidants, ram, semen, thawing, ascorbic acid, reactive oxygen species, melatonin, sheep, Trolox C.

RESUMO-- Objetivou-se avaliar o efeito da adição dos antioxidantes ácido ascórbico, melatonina e Trolox C, associados ao sêmen diluído de carneiros sobre o estresse oxidativo e o potencial fecundante após criopreservação. Foram cole-

\footnotetext{
${ }^{1}$ Recebido em 14 de junho de 2016.

Aceito para publicação em 18 de novembro de 2016

${ }^{2}$ Programa de Pós-Graduação em Ciências Veterinárias, Universidade Estadual do Ceará (UECE), Campus do Itaperi, Avenida Dr. Silas Muguba 1700, Fortaleza, CE 60740-000, Brasil. E-mail: wilde@zootecnista.com.br

${ }^{3}$ Programa de Pós-Graduação em Ciência Animal, Universidade Federal do Vale do São Francisco (Univasf), Projeto Nilo Coelho C1, Rodovia 407 Km 12, Lote 543, Petrolina, PE 56300-000, Brasil. *Autor para correspondência: elenice.moraes@univasf.edu.br
}

tados 10 ejaculados de 3 carneiros (n=30) e diluídos em Tris-Gema de ovo até a concentração final de $200 \times 10^{6} \mathrm{sptz} /$ $\mathrm{mL}$ e, mantidos em banho maria a $32^{\circ} \mathrm{C}$. Os antioxidantes foram adicionados da seguinte forma: controle (sem adição de antioxidantes); $100 \mu \mathrm{M}$ de melatonina (MEL) + 0,05\% de ácido ascórbico (AA); $100 \mu \mathrm{M}$ de MEL $+90 \mu \mathrm{L}$ de Trolox C (TRO); $90 \mu \mathrm{L}$ de TRO + 0,05\% de AA; e $100 \mu \mathrm{M}$ de MEL $+0,05 \% \mathrm{AA}+90 \mu \mathrm{L}$ de TRO. Depois, o sêmen foi resfriado em câmara fria a $5^{\circ} \mathrm{C}$ por duas horas, após esse período, envasado e lacrado em palhetas de $0,5 \mathrm{~mL}$, e então acondicionado sob vapor de nitrogênio liquido $\left(\mathrm{N}_{2} \mathrm{~L}\right)$, a $8 \mathrm{~cm}$ da lâmina líquida por 15 minutos, e depois imersos no $\mathrm{N}_{2} \mathrm{~L}$. As amostras foram analisadas quanto à motilidade esper- 
mática, integridade da membrana plasmática e da membrana acrossomal, atividade mitocondrial, teste de ligação e a quantificação do estresse oxidativo. As variáveis foram submetidas à análise de variância e medias comparadas pelo teste de Tukey a $5 \%$ de probabilidade. A motilidade (total e progressiva) foi maior $(\mathrm{P}<0,05)$ quando adicionado à associação MEL+AA+TRO (67\% e 49,89\%), MEL+AA $(64,37 \%$ e $45,61 \%)$ e MEL+TRO $(61,65 \%$ e $41,15 \%)$ comparado ao tratamento controle $(55,52 \%$ e $36,54 \%)$ e TRO+AA $(57,07 \%$ e 38,40\%). A adição de MEL+AA+TRO ao sêmen diluído manteve $(\mathrm{P}<0,05)$ a integridade da membrana plasmática $(30,75 \%)$ e acrossomal $(84,53 \%)$ dos espermatozoides quando comparado ao tratamento controle $(15,60$ e $68,16 \%$, respectivamente), além de ter promovido maior $(\mathrm{P}<0,05)$ atividade mitocondrial $(96,43 \%)$ quando comparado aos demais tratamentos. 0 número de espermatozoides que apresentaram à capacidade de ligação a membrana perivitelina da gema de ovo foi maior $(\mathrm{P}<0,05)$ no sêmen tratado com as diferentes associações de antioxidante quando comparado ao controle, sendo a associação MEL+AA+TRO $(178,36 \%)$ superior $(\mathrm{P}<0,05)$ aos demais tratamentos. Não houve diferença $(P>0,05)$ entre os tratamentos quanto a quantidade de espécies reativas ao ácido tiobarbitúrico produzidos. Conclui-se que a adição de MEL+AA+TRO ao sêmen diluído de carneiros, nas doses avaliadas, melhora a qualidade espermática após descongelação.

TERMOS DE INDEXAÇÃO: Antioxidantes, sêmen, carneiro, descongelação, ácido ascórbico, espécies reativas de oxigênio, melatonina, ovinos, Trolox C.

\section{INTRODUÇÃo}

A inseminação artificial (IA) em ovinos utilizando sêmen congelado/descongelado apresenta uma limitação devido aos baixos índices de fecundidade obtidos, quando utilizado o sêmen a fresco ou resfriado (Da Silva Maia et al. 2009), uma vez que o processo de congelação/descongelação danifica cerca de 50\% das células (Souza et al. 2016). Nos últimos anos, além dos danos ultraestruturas, bioquímicos e funcionais, os estudos associaram os baixos índices de fecundidade as espécies reativas de oxigênio (EROs) as quais são produzidas durante o processo de congelação/ descongelação da célula espermática (Chatterjee \& Gagnon 2001, Sarlós et al. 2002, Kasimanickam et al. 2006, Bucak et al. 2008, Souza et al. 2016). Sendo os espermatozoides de ovino, susceptíveis ao estresse oxidativo, devido à elevada concentração de ácidos graxos poli-insaturados presentes na membrana plasmática (Bucak et al. 2007).

0 estresse oxidativo resultante da elevada concentração de EROs no sêmen pode afetar o metabolismo de energia, a motilidade, viabilidade e a integridade do DNA integridade (Krzyzosiak et al. 2000, Baumber et al. 2002, Bilodeau et al. 2002). Dessa maneira, as células espermáticas podem ter estresse oxidativo adicional, tornando necessária a proteção exógena (Taylor 2001), por possuírem poucos mecanismos capazes de evitar parcialmente ou totalmente a produção de EROs, e prevenir a peroxidação excessiva dos substratos (Silva 2006). Desta forma, a proteção antio- xidante adicional nas células espermáticas, durante a maturação e o armazenamento, quando as células necessitam combater o estresse oxidativo e, ao mesmo tempo, manter a habilidade de produção de EROs para execução de seus processos fisiológicos (Drevet 2006) é necessário. Assim, antioxidantes não enzimáticos como Trolox C, ácido ascórbico e a melatonina podem ser utilizados para prevenir a oxidação e aumentar a capacidade fecundante dos espermatozoides (Costa et al. 2016, Souza et al. 2016).

Tem sido observado que o Trolox $C$ é um excelente inibidor da lipoperoxidação, devido ao fato de distribuir-se nas camadas duplas de lipídeos das biomembranas, envolvendo o $\mathrm{OH}^{-}$fenólico e proporcionando a remoção de radicais peroxil (Albertini \& Abuja 1999). Da mesma forma, o ácido ascórbico apresenta característica hidrossolúvel e a capacidade de neutralizar as EROs, inibindo a peroxidação lipídica por redução (Barreiros et al. 2006) que ocorre na fase aquosa nos radicais livres (Castilho et al. 2009). Já a melatonina, tem capacidade quelante dos radicais livres, eficiência na redução de perda de elétrons de cadeia de transporte mitocondrial, e de sua ação sinérgica com outros antioxidantes (Reiter et al. 2007).

Assim, a adição de antioxidante no sêmen diluído protege os espermatozoides de ovinos das crioinjúrias durante o período de criopreservação (Souza et al. 2016), no entanto, na busca realizada pelos autores não foram encontrados trabalhos sobre o tema em ovinos. Portanto, objetivou-se avaliar o efeito da adição de antioxidantes associados ao sêmen diluído de carneiros sobre o estresse oxidativo e o potencial fecundante após criopreservação.

\section{MATERIAL E MÉTODOS}

Ética. O presente estudo foi realizado após a aprovação institucional da Universidade Federal do Vale do São Francisco (Univasf), sob o protocolo no $0005 / 140813$, estando de acordo com os princípios éticos de experimentação animal adotados pelo Comitê de Ética e Deontologia em Estudos e Pesquisas da Univasf.

Reagentes. Todos os reagentes químicos foram adquiridos a partir da Sigma-Aldrich (Recife, PE).

Local de execução. 0 experimento foi realizado durante os meses de Maio a Junho de 2016, no setor de Ovinocultura e no Centro de Pesquisa em Suínos, Espécies Nativas e Silvestre (CPSENS), localizados no Campus de Ciências Agrárias da Univasf, situados no munícipio de Petrolina-PE (latitude 09²3'55" Sul e a uma longitude $40^{\circ} 30^{\prime} 03^{\prime \prime}$ Oeste), estando a uma altitude de $376 \mathrm{~m}$, com precipitação média anual em torno de $300 \mathrm{~mm}$. A região apresenta temperatura média anual em torno dos $27^{\circ} \mathrm{C}$ e clima do tipo Bsh segundo a classificação de Peel et al. (2007).

Animais. Foram utilizados três carneiros adultos, sendo dois da raça Dorper e um da raça Santa Inês, com idade entre dois a quatro anos, selecionados por meio de exame andrológico, onde todos apresentaram características espermáticas acima dos padrões mínimos para a espécie, conforme estabelecido pelo Colégio Brasileiro de Reprodução Animal (CBRA 2013).

Os carneiros foram confinados em uma instalação contendo acesso a iluminação natural, com dimensão de $2 \times 3 m$ de área coberta e com área de solário de $2 \times 4 \mathrm{~m}$, apresentando temperatura e umidade relativa média durante o período experimental de $27,3^{\circ} \mathrm{C}$ e $47,5 \%$, respectivamente. Os carneiros foram mantidos isolados das fêmeas, recebendo água ad libitum e alimentação fornecida duas vezes ao dia, com dieta composta de capim elefante 
(Penissetum purpureum) picado, além de suplementação concentrada a base de farelo de milho, farelo de soja e mistura mineral. A relação volumoso:concentrado foi de 60:40 na forma de dieta total misturada, de acordo com as exigências para animais desta categoria segundo o NRC (NRC 2007).

Coleta e processamento do sêmen. Foram coletados 10 ejaculados de cada carneiro $(n=30)$, por meio de vagina artificial para ovinos (Minitub ${ }^{\circledR}$, Berlin, Alemanha). As coletas foram realizadas duas vezes por semana para cada animal. Após a coleta, o ejaculado foi transportado em uma caixa térmica para o CPSENS, mantido em banho maria a $32^{\circ} \mathrm{C}$, e avaliado: aspecto (cremoso, leitoso, opalescente ou aquoso), volume (mL), motilidade (0 a 100\%), vigor ( 0 a 5) e concentração (espermatozoides $/ \mathrm{mL}$ ), atendendo aos padrões considerados normais pelo CBRA (CBRA 2013).

$\mathrm{O}$ aspecto foi classificado por observação visual em cremoso, leitoso, opalescente ou aquoso, de acordo com Mies Filho (1987). 0 volume foi mensurado por pipetagem. A motilidade espermática (total e progressiva) foi determinada utilizando o sistema de análise computadorizada (CASA ${ }^{\circledR}$, Minitub, Berlin, Alemanha), equipado com o SpermVision ${ }^{\circledR}$, onde $8 \mu \mathrm{L}$ do ejaculado foi pré-

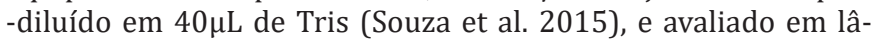
mina e lamínula pré-aquecidas a $37^{\circ} \mathrm{C}$. Para avaliar o vigor, $10 \mu \mathrm{L}$ do ejaculado pré-diluido foi avaliado em lâmina e lamínula pré-aquecidas a $37^{\circ} \mathrm{C}$ e observado em microscopia optica de luz, com aumento de 200x, onde foi utilizada a classificação: 0 (sem movimento progressivo) a 5 (movimento rapido e progressivo) (CBRA 2013). A concentração espermática foi determinada utilizando $4 \mu \mathrm{L}$ do do ejaculado foi diluído em $4 \mathrm{~mL}$ de água destilada em microcuvetas próprias para o fotometro SpermaCue ${ }^{\circledR}$ (Modelo SMD6, Minitub, Berlin, Alemanha), devidamente calibrado para sêmen de ovinos. Em seguida procedia-se a leitura automatizada, para obter a taxa de diluição para a concentração de $200 \times 10^{6}$ espermatozoides/mL.

Após avaliação, os ejaculados aprovados foram subdivididos em cinco tubos de ensaio e diluídos em Tris-Gema de ovo e glicerol, conforme a concentração utilizada por Souza et al. (2015), para a concentração final de $200 \times 10^{6}$ espermatozoides $/ \mathrm{mL}$ e mantidos em banho maria a $32^{\circ} \mathrm{C}$.

A melatonina foi dissolvida utilizando dimetilsulfóxido (DMSO) e tampão fosfato-salino (PBS), conforme Souza et al. (2016), e para a utilização do antioxidante Trolox C foi feito conforme descrito por Maia et al. (2009). Para determinação dos tratamentos experimentais, os antioxidantes foram adicionados ao sêmen diluído, estabelecendo assim os tratamentos: controle (sem adição de antioxidantes); $100 \mu \mathrm{M}$ de melatonina (MEL) + $0,05 \%$ de ácido ascórbico (AA); $100 \mu \mathrm{M}$ de MEL $+90 \mu \mathrm{L}$ de Trolox C (TRO); $90 \mu \mathrm{L}$ de TRO + 0,05\% de AA; e 100 $\mu \mathrm{M}$ de MEL + 0,05\%AA $+90 \mu \mathrm{L}$ de TRO.

Após adição dos antioxidantes, as amostras de cada tratamento foram colocadas em Becker de $100 \mathrm{~mL}$ com água a $32^{\circ} \mathrm{C}$, ficando acima do volume das amostras, e então acondicionadas em câmara fria a $5^{\circ} \mathrm{C}$ por duas horas. Depois, as amostras de cada tratamento foram envasadas em palhetas de $0,5 \mathrm{~mL}$ e lacradas com seladora (UltraSeal ${ }^{\circledR}$, Minitub, Berlin, Alemanha) e acondicionadas sob vapores do nitrogênio liquido, por 15 minutos, a $8 \mathrm{~cm}$ da lâmina líquida. Decorrido este tempo, as palhetas foram imersas no nitrogênio líquido e estocadas em botijão criogênico para posterior análise.

Descongelação do sêmen. A descongelação foi feita em 30 segundos utilizando o descongelador automático de palhetas (IMV, São Paulo, SP) programado para temperatura de $37^{\circ} \mathrm{C}$.

Avaliação da motilidade espermática. Amostras (duas palhetas) descongeladas de cada tratamento foram avaliadas para a motilidade espermática (total e progressiva) utilizando o CASA, conforme descrito anteriormente.
Avaliação da integridade da membrana plasmática. A integridade da membrana plasmática dos espermatozoides descongelados foi realizada utilizando duas sondas fluorescentes, iodeto de propídio (IP) e Hoechst 33342 (H33342), conforme descrito por Graham et al. (1990). Dez microlitros de cada amostra (duas palhetas) descongelada dos tratamentos foram colocados em microtubo de $1,5 \mathrm{~mL}$, onde foram adicionados $2 \mu \mathrm{L}$ de IP e de H33342, e depois incubado em banho maria a $37^{\circ} \mathrm{C}$ durante 8 minutos. Em seguida, foram retirados $10 \mu \mathrm{L}$ da amostra que foi incubada e colocada entre lâmina e lamínula pré-aquecidas a $37^{\circ} \mathrm{C}$ para ser avaliado em microscópio de fluorescência (AXIO Image $\mathrm{A} 2^{\circledR}$, Carl Zeiss, Berlin, Alemanha) quanto ao percentual de espermatozoides com membrana plasmática integra: intacta (apresentavam o núcleo corado de azul) ou lesada (núcleo corado de rosa). Para cada amostra analisada, um total de 200 células foi contado em campos aleatórios.

Avaliação da membrana acrossomal. A integridade do acrossoma foi avaliada utilizando o fluorocromo (isoticianato de fluoresceína - FITC), conjugado a uma lecitina (peanut agglutinin - PNA) e associado a um fluorocromo que tem afinidade pelo DNA (iodeto de propídeo - IP) (Casey et al. 1993). Está técnica permite distinguir os espermatozoides vivos e/ou mortos com acrossoma intacto ou reagido.

Das amostras (duas palhetas) de cada tratamento descongelado, $10 \mu \mathrm{L}$ foi retirado e colocado em microtubo de $1,5 \mathrm{~mL}$, onde foram adicionados $10 \mu \mathrm{L}$ de FITC-PNA e de IP, e incubado em banho maria a $37^{\circ} \mathrm{C}$ durante 20 minutos. Em seguida, $10 \mu \mathrm{L}$ da amostra incubada foi colocada entre lâmina e lamínula pré-aquecidas a $37^{\circ} \mathrm{C}$ e avaliada em microscópio de fluorescência (AXIO Image $\mathrm{A} 2^{\circledR}$, Carl Zeiss, Berlin, Alemanha), utilizando filtro de fluoresceína de excitação de $365 \mathrm{~nm}$ e de emissão de $420 \mathrm{~nm}$. Para cada campo selecionado, um total de 200 células por amostra em campos aleatórios da lâmina foi contado.

O PNA possui a capacidade de se ligar à membrana acrossomal externa do espermatozoide com acrossoma reagido ou danificado. O IP penetra nos espermatozoides com membrana lesada, ligando-se ao DNA, indicando os espermatozoides vivos ou mortos. Dessa forma, os espermatozoides foram classificados em: espermatozoides mortos com acrossoma intacto (corados de vermelho do IP); espermatozoides mortos com acrossoma reagido ou danificado (corados de vermelho do IP, com região acrossomal corada de verde do FITC-PNA); espermatozoides vivos com acrossoma intacto (não observados em fluorescência, apenas em campo claro); espermatozoides vivos com acrossoma reagido ou danificado (corados de verde do FITC-PNA).

Avaliação da atividade mitocondrial. A atividade mitocondrial (AM) foi determinada utilizando a sonda Rodamina 123 (R123). Onde a sonda fluorescente é transportada e acumulada no interior das mitocôndrias com respiração ativa (mitocôndrias funcionais), emitindo fluorescência verde (Graham et al. 1990).

Das amostras (duas palhetas) de cada tratamento descongeladas, alíquota de $10 \mu \mathrm{L}$ foram retiradas e colocadas em microtubo de $1,5 \mathrm{~mL}$, onde foram adicionados $2 \mu \mathrm{L}$ de R123, e incubadas em banho maria a $37^{\circ} \mathrm{C}$ durante 8 minutos. Em seguida, $10 \mu \mathrm{L}$ de cada amostra incubada foi adicionado entre lâmina e lamínula pré-aquecidas a $37^{\circ} \mathrm{C}$ e avaliadas em microscópio de fluorescência (AXIO Image $\mathrm{A} 2^{\circledR}$, Carl Zeiss, Berlin, Alemanha), utilizando filtro de fluoresceína de excitação de 400-570 e de emissão de 460-610nm. Um total de 200 espermatozoides por amostra em campos aleatórios da lâmina foi considerado para determinar as avaliações.

Teste de ligação. A capacidade dos espermatozoides de ovino se ligar a membrana de oócitos foi avaliada utilizando a membrana perivitelina da gema de ovo de galinha (CEPM), descrito por Santos et al. (2015). Brevemente, a preparação das membranas 
perivitelinas (MPVs) foi realizada por meio da separação da gema de ovo da clara, e o excesso de clara removido com auxílio de um papel toalha. Em seguida, a gema de ovo ainda intacta, foi colocada sobre uma folha de parafilme, para facilitar o rompimento da membrana e sua lavagem com TALP, conforme descrito por Graham et al. (1986) para retirada da gema de ovo. A membrana foi removida do parafilme e colocada em uma placa de Petri de vidro, onde foi lavada algumas vezes com TALP até a solução ficar clara e sem resíduo de gema de ovo. Em seguida, a MPV foi cuidadosamente aberta e cortada com lamina de bisturi em pequenos fragmentos $(1 \mathrm{x} 1 \mathrm{~cm})$, utilizando uma cubeta de vidro de espectrofotômetro. Cada fragmento de MPV cortado foi imerso em TALP colocados em tubos plásticos de $1 \mathrm{~mL}$.

Para realização do teste de ligação de membrana, nos tubos de ensaio contendo as MPVs foram adicionados $10 \mu \mathrm{L}$ de cada tratamento. Os espermatozoides foram corados com Hoechst 33342 e preparado 1 hora antes da inseminação. 0 sêmen $(2 \mathrm{~mL}$ de sêmen fresco diluídos em Tris-Gema de ovo até a concentração de 120 $\times 10^{6}$ espermatozoides) foi centrifugado a $400 \times \mathrm{g}$ durante $5 \mathrm{mi}$ nutos, o sobrenadante removido e o pellet foi resuspendido com $1 \mathrm{~mL}$ de TALP contendo $35 \mu \mathrm{L} / \mathrm{mL}$ de Hoechst 33342 . 0 sêmen foi incubado em banho maria a $37^{\circ} \mathrm{C}$ durante 15 minutos e em seguida centrifugado a $400 \times \mathrm{g}$ por 5 minutos e novamente o pellet foi resuspendido com TALP até a concentração de $5 \times 10^{6}$ espermatozoides/mL.

Cada MPV inseminada foi incubada a $37^{\circ} \mathrm{C}$ com uma atmosfera de $5 \%$ de $\mathrm{CO}_{2}$ por 90 minutos, sendo que a cada 30 minutos os tubos foram lentamente agitados para que a membrana permanecesse aberta. Passados 70 minutos de incubação, $10 \mu \mathrm{L}$ de Hoechst 33342 (1 mg/mL em PBS) foi adicionado em cada tubos para corar de azul os espermatozoides. Após a incubação, cada membrana foi transferida para outro tubo contendo $1 \mathrm{~mL}$ de TALP para lavagem e remoção dos espermatozoides que não se ligaram, sendo repetido por 5 vezes esta etapa. Depois, as MPVs de cada tratamento foram abertas em lâmina e coberta com lamínula, e observada em microscópio de fluorescência (AXIO Image $\mathrm{A} 2^{\circledR}$, Carl Zeiss, Berlin, Alemanha), utilizando filtro de fluoresceína de excitação $365 \mathrm{~nm}$ e de emissão 420nm.

A capacidade de ligação dos espermatozoides de cada tratamento, obtido pelo número de espermatozoides ligados à MPV, foi determinada contando seis campos aleatórios de cada fragmento da MPV, e a eficiência de ligação à MPV foi calculada pela divisão do número total de espermatozoides ligados àquela particular MPV pelo número de espermatozoides ligados a mesma membrana pelo grupo controle.

Avaliação da resistência ao estresse oxidativo. Para essa avaliação, as amostras (duas palhetas) por tratamento foram descongeladas como descrito acima e o conteúdo esvaziado em microtubo de $1,5 \mathrm{~mL}$. Para remoção do crioprotetor foi realizada a centrifugação duas vezes a $800 \times$ g durante 10 minutos, e o pellet resuspendido com $1 \mathrm{~mL}$ da solução fisiológica ( $\mathrm{NaCl}$ 0,9\%). Em seguida, $0,4 \mathrm{~mL}$ da suspensão foi pipetado e adicionado em tubo de vidro $(4 \mathrm{~mL})$, onde a peroxidação lipídica foi induzida pela adição de $100 \mu \mathrm{L}$ de ácido ascórbico $(20 \mathrm{mM})$ e $100 \mu \mathrm{L}$ de sulfato de ferro $(4 \mathrm{mM})$, e incubando em banho maria a $37^{\circ} \mathrm{C}$ durante 120 minutos (Gomez et al. 1998).

Após esse período, 0,5mL de cada amostra incubada foram retirados e adicionado em microtubo de $2 \mathrm{~mL}$, onde foi adicionado $1 \mathrm{~mL}$ de solução gelada de ácido tricloroacético a 10\%, e depois centrifugados a $18.000 \times$ g por $15 \mathrm{~min}$ a $15^{\circ} \mathrm{C}$ (Centrifuge 5430r, Eppendorf AG, Hamburg, Alemanha), para separação de proteínas precipitantes que pudessem interferir na leitura (Souza et al. 2016). Após a centrifugação, $1 \mathrm{~mL}$ do sobrenadante foi retirado e adicionado em tubo de vidro ( $4 \mathrm{~mL}$ ) onde foi misturado com $1 \mathrm{~mL}$ de ácido tiobarbitúrico (TBA) a 1\%, dissolvido em hidróxi- do de sódio (0,05 $\mathrm{N}$ de $\mathrm{NaOH})$, preparado instantes antes de ser utilizado. Em seguida a mistura foi incubada em banho maria a $90^{\circ} \mathrm{C}$ durante 15 minutos, e imediatamente ao término, resfriado em banho de gelo para interromper a reação termo dependente, e sendo feita a leitura em espectrofotômetro Q898DRM $5^{\circledR}$ (Quimis, São Paulo, SP) em comprimento de onda de $532 \mathrm{~nm}$ para quantificar as espécies reativas ao ácido tiobarbitúrico (TBARS).

0 principal produto de peroxidação lipídica medido por este método foi o malondialdeído (MDA). As medições de MDA foram efetuadas em conformidade com um protocolo inicialmente descrito por Ohkawa et al. (1979). 0 método baseia-se na reação de duas moléculas de TBA com uma molécula de MDA, a altas temperaturas e baixo $\mathrm{pH}$, resultando em um cromogênio de cor rosa que o identifica para ser quantificado pelo espectrofotômetro.

Os valores obtidos foram transformados para a concentração de TBARS nas amostras ( $\mu \mathrm{M}$ de MDA $\left./ 10^{6} \mathrm{sptz}\right)$ comparando-os com a solução padrão feita previamente com MDA.

Análise estatística. 0 delineamento foi inteiramentamente casualizado em ensaio fatorial 3x5 (3 animais x 5 tratamentos). As análises dos parâmetros avaliados foram avaliadas utilizando-se o programa SAS 2002-2008. Versão 9.2, by SAS Institute Inc. (Cary, NC, USA). Todas as variáveis foram submetidas aos testes de normalidade (Teste de Lilliefors) e homocedacidade (Teste de Cochran e Bartlett), posteriomente as variáveis de distribuição normal foram submetidas à análise de variância e as médias comparadas pelo teste de Tukey com nível de significância de 5\%. Os dados da capacidade de ligação dos espermatozoides foram transformados antes da análise por transformação da raiz quadrada para ajustar para variâncias desiguais. A percentagem de espermatozoides móveis de cada tratamento ligados a MPV foram submetidas à análise de variância e médias comparadas pelo teste de Tukey. Para determinar o potencial de ligação de cada tratamento, os dados foram também normalizados para obter a porcentagem de espermatozoides móveis que foram adicionados em cada MPV, dividindo-se o número de espermatozoides ligados em cada MPV pela percentagem de espermatozoides móveis em cada MPV.

\section{RESULTADOS}

A motilidade total e progressiva dos espermatozoides descongelados foi maior $(P<0,05)$ nos espermatozoides que receberam no sêmen diluído MEL+AA+TRO, MEL+AA e MEL+TRO quando comparado ao controle e TRO+AA (Figura 1).

A adição das diferentes associações de antioxidantes no sêmen diluído manteve $(\mathrm{P}<0,05)$ a integridade da membrana plasmática e acrossomal dos espermatozoides quando comparado ao controle (Quadro 1). A atividade mitocondrial foi maior $(\mathrm{P}<0,05)$ nos espermatozoides que recebe-

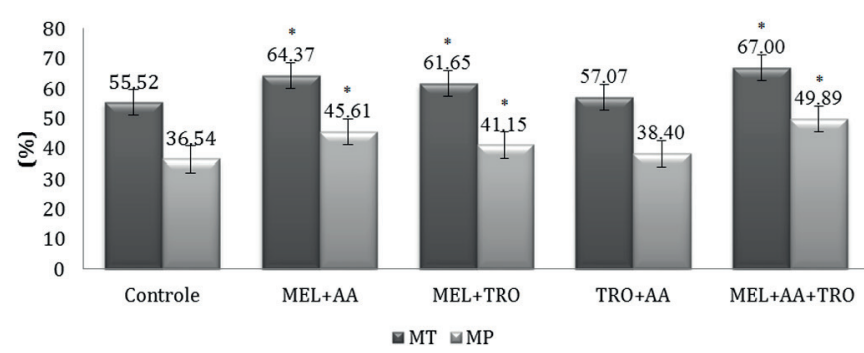

Fig.1. Motilidade total (MT) e progressiva (MP) (média \pm D.P) de espermatozoides descongelados de ovinos após adição de diferentes associações de antioxidantes no sêmen diluído. $(\mathrm{P}<0,05)$. $\mathrm{MEL}=$ melatonina, $\mathrm{AA}=$ ácido ascórbico, $\mathrm{TRO}=$ Trolox $\mathrm{C}$. 
Quadro 1. Integridade da membrana plasmática (iMP), integridade acrossomal (iAC) e atividade mitocondrial (AM) (média \pm D.P \%) de espermatozoides descongelados de ovinos após adição de diferentes associações de antioxidantes no sêmen diluído

\begin{tabular}{lccc}
\hline Antioxidantes & iMP & iAC & AM \\
\hline Controle & $15,60 \pm 3,51^{\mathrm{C}}$ & $68,16 \pm 3,55^{\mathrm{C}}$ & $88,55 \pm 3,10^{\mathrm{C}}$ \\
MEL+AA & $27,10 \pm 3,72^{\mathrm{AB}}$ & $74,45 \pm 3,66^{\mathrm{B}}$ & $92,23 \pm 2,74^{\mathrm{B}}$ \\
MEL+TRO & $23,33 \pm 3,13^{\mathrm{B}}$ & $78,23 \pm 3,49^{\mathrm{B}}$ & $92,48 \pm 2,63^{\mathrm{B}}$ \\
TRO+AA & $22,69 \pm 3,11^{\mathrm{B}}$ & $75,18 \pm 3,32^{\mathrm{B}}$ & $89,75 \pm 2,52^{\mathrm{BC}}$ \\
MEL+AA+TRO & $30,75 \pm 3,09^{\mathrm{A}}$ & $84,53 \pm 3,18^{\mathrm{A}}$ & $96,43 \pm 3,03^{\mathrm{A}}$
\end{tabular}

$\overline{A, B, C}$ Médias seguidas de letras diferentes na mesma coluna diferem entre si pelo teste Tukey $(\mathrm{P}<0,05) . \mathrm{MEL}=$ melatonina, $\mathrm{AA}=$ ácido ascórbico, TRO $=$ Trolox $\mathrm{C}$.

Quadro 2. Número (média \pm D.P) de espermatozoides descongelados de ovinos ligados à membrana perivitelina de gema de ovo (NEL) e sua eficiência de ligação (EFL) após adição de diferentes associações de antioxidantes no sêmen diluído

\begin{tabular}{lccc}
\hline Antioxidantes & NEL & EFL & Valor de P \\
\hline Controle & $115,46 \pm 3,24^{\mathrm{C}}$ & 1,00 & P $<0,05$ \\
MEL+AA & $168,87 \pm 3,11^{\mathrm{B}}$ & 1,46 & \\
MEL+TRO & $164,15 \pm 3,54^{\mathrm{B}}$ & 1,42 & \\
TRO+AA & $160,96 \pm 3,12^{\mathrm{B}}$ & 1,39 & \\
MEL+AA+TRO & $178,36 \pm 3,72^{\mathrm{A}}$ & 1,54 &
\end{tabular}

$\overline{A, B, C}$ Médias seguidas de letras diferentes na coluna diferem entre si pelo teste Tukey $(\mathrm{P}<0,05) . \mathrm{MEL}=$ melatonina, $\mathrm{AA}=$ ácido ascórbico, $\mathrm{TRO}=$ Trolox C.

Quadro 3. Número (média \pm D.P) de espécies reativas ao ácido tiobarbitúrico (TBARS) (média \pm D.P) geradas em espermatozoides descongelados de ovinos após adição de diferentes associações de antioxidantes no sêmen diluído

\begin{tabular}{lcc}
\hline Antioxidantes & TBARS $\left(\mu \mathrm{M}\right.$ de MDA $/ 10^{6}$ sptz $)$ & Valor de P \\
\hline Controle & $4,03 \pm 0,45$ & P $>0,05$ \\
MEL+AA & $3,47 \pm 0,65$ & \\
MEL+TRO & $3,55 \pm 0,55$ & \\
TRO+AA & $3,14 \pm 0,77$ & \\
MEL+AA+TRO & $3,92 \pm 0,53$ &
\end{tabular}

MEL = melatonina, $\mathrm{AA}=$ ácido ascórbico, $\mathrm{TRO}=$ Trolox $\mathrm{C}, \mathrm{MDA}=$ malondialdeído.

ram a associação de MEL+AA+TRO comparado aos demais tratamentos (Quadro 1).

0 número de espermatozoides que apresentaram capacidade de ligação à membrana perivitelina da gema de ovo durante o teste de ligação foi maior $(\mathrm{P}<0,05)$ no sêmen diluído tratado com as diferentes associações de antioxidante quando comparado ao controle, sendo a associação MEL+AA+TRO superior aos demais tratamentos (Quadro 2).

Não foi observado diferença $(\mathrm{P}>0,05)$ entre os tratamentos sobre a quantidade de TBARS produzidos (Quadro 3).

\section{DISCUSSÃO}

0 armazenamento por tempo indeterminado de espermatozoides para posterior utilização na IA, exige que esses sejam mantidos no estado congelado (Keshtgar et al. 2016). No entanto, apesar dos avanços ao longo dos anos, como a melhoria dos métodos de congelação/descongelação, a criopreservação de espermatozoides ovinos ainda apre- senta uma redução na qualidade espermática após a descongelação. Assim, o presente estudo investigou o efeito da adição de antioxidantes associados na proteção contra as EROs e melhoria na qualidade espermática, uma vez que o desequilíbrio entra a presença de EROs e a atividade antioxidante no sêmen, é a principal causa de crioinjúrias nos espermatozoides (Li et al. 2010).

0 efeito antioxidante da melatonina nas células tem sido frequentemente explicado devido a sua capacidade de neutralizar uma grande quantidade de radicais livres tóxicos (Peyrot \& Ducrocq 2008, Hardeland et al. 2009, Souza et al. 2016) e influenciar a expressão gênica de enzimas antioxidantes, que elevam os níveis de RNA mensageiro e de proteínas dessas enzimas (Reiter et al. 2000). Todavia, o mecanismo de ação antioxidante do ácido ascórbico ocorre por meio de sua capacidade redutora como doador de elétrons (Bielski et al. 1975). Outro importante mecanismo de ação é na recuperação da vitamina E (alfa-tocoferol). Na reação antioxidante da vitamina E com as EROs ocorre a formação do radical alpha-tocoferoxil que pode ser reduzido pelo ácido ascórbico de volta para a forma de alfa-tocoferol (Neuzil et al. 1997). Já o Trolox C, análogo da vitamina E, que por meio de sua propriedade antioxidante, atua como captador de radicais peróxido de lipídeos (Ross et al. 1995), evitando assim a peroxidação lipídica. Por outro lado, o Trolox C é capaz de inibir a lipoperoxidação através da neutralização de radicais peróxil e radicais alcoxil encontrados nas membranas que resultam em morte celular (Pereira et al. 2003).

$O$ efeito antioxidante da MEL+AA+TRO foi observado por meio de diferentes avaliações realizadas, onde para a motilidade total e progressiva foi verificado que os valores percentuais aumentaram com a adição da melatonina no sêmen diluído, associada tanto com o ácido ascórbico, como com o Trolox C, sendo as melhorias mais expressivas com a associação dos três antioxidantes. Tais resultados demonstram os benefícios individuais de cada antioxidante e que pode ser potencializado quando da associação deles.

Nos espermatozoides, a produção de ATP supre várias atividades celulares e eventos bioquímicos, necessários para que a fecundação seja bem sucedida, tais como a capacitação, reação acrossômica e a motilidade espermática (Miki 2007). Dessa forma, os valores elevados de motilidade espermática podem ser atribuidos a maior disponiblidade de ATP, observada após a criopreservação na associação MEL+AA+TRO. Além disso, como a geração de ATP dentro das mitocôndrias é um processo dependente de membrana, qualquer dano na membrana espermática, afeta negativamente a geração de ATP mitocondrial e, consequentemente, a atividade mitocondrial (Maia et al. 2009). Assim, o efeito protetor exercido pelos antioxidantes sobre os espermatozoides, manteve altos os níveis de ATP, para que assim, os espermatozoides, apresentem a capacidade necessária para se deslocar no trato genital feminino.

A associação Trolox $\mathrm{C}$ e ácido ascórbico sobre a motilidade espermática, não houve o efeito antioxidante esperado, e isso pode ser atribuído a dois fatores, o primeiro à dose utilizada, pois os dois antioxidantes atuam em regiões diferentes da célula, sendo o Trolox C na bicamada lipídica e o ácido ascórbico na fase aquosa da membrana celular, su- 
gerindo que a dose aplicada nesse estudo para cada antioxidante, não apresentou um nível de concentração necessário para exercer uma atividade antioxidante nas especificas regiões. $\mathrm{O}$ segundo fator, a ausência da melatonina nessa associação. Embora o Trolox C e o ácido ascórbico tenham importantes propriedades antioxidantes, em nossos resultados a adição da melatonina como um antioxidante endógeno, seja com o Trolox C e/ou com ácido ascórbico resultou em melhores resultados. Como reportado por Asharfi et al. (2013), a presença da melatonina aumenta a capacidade antioxidante total, por meio da elevação da atividade das enzimas antioxidantes, já que ela é capaz de estimular várias enzimas (superóxido dismutase, glutationa peroxidade e catalase) envolvidas no metabolismo das EROs, proporcionando, assim, aumento da motilidade espermática.

A membrana plasmática dos espermatozoides contém uma quantidade elevada de ácidos graxos insaturados, e por isso são particularmente susceptíveis ao estresse oxidativo (Khalil et al. 2013). Alterações morfológicas na membrana plasmática durante a criopreservação levam à peroxidação da bicamada lipídica, por conta da elevada produção de EROs, produzidas durante o processo de congelação-descongelação (Sariozkan et al. 2010). A peroxidação lipídica destrói a estrutura matriz dos lipídeos nas membranas dos espermatozoides (Sharma \& Agarwal 1996). Os resultados demonstram que a adição das associações dos antioxidantes no sêmen diluído antes do processo de congelação e descongelação neutralizam os efeitos de peroxidação lipídica nesta etapa sobre a integridade da membrana plasmática dos espermatozoides. Como pode ser constatado, a associação MEL+AA+TRO promoveu maior resistência aos danos oxidativos e a lesões durante as mudanças de temperatura, estabilizando assim, a fluidez da membrana plasmática e preservando a sua integridade durante a criopreservação.

Diante dos resultados encontrados podemos constatar que houve melhoria da capacidade antioxidante total e a elevação da atividade das enzimas antioxidantes, quando a associação dos antioxidantes melatonina com ácido ascórbico e Trolox C foi utilizada. Esse efeito protetor, está associado com a redução da peroxidação lipidica (Ashrafi et al. 2013) e a inibição da ruptura na membrana, causada durante a redução de temperatura (Lei et al. 2004). Assim, o uso de Trolox C, do grupo de substâncias antioxidantes lipossolúveis, juntamente com a propriedade hidrossolúvel da vitamina $C$, além da propriedade anfifílica da melatonina, faz com que a associação dessas três substâncias, resulte em um potente antioxidante endógeno, capaz de atravessar as membranas espermáticas. A associação desses antioxidantes promoveu o acesso a compartimentos intracelulares e funcionando como potentes removedores de radicais livres, proporcionando, assim, uma melhor preservação da integridade da membrana plasmática.

0 aumento do percentual de espermatozoides com acrossoma integro foi constatado nas associações dos diferentes antioxidantes, devido ao efeito estimulatório desses, que atuam em diferentes partes da célula contra o dano oxidativo, além de elevar a atividade das enzimas que participam na defesa antioxidante. Além disso, com base nos resultados, o efeito da associação dos antioxidantes sobre essa região do espermatozoide, observado nas características exclusivas obtidas com a associação MEL+AA+TRO, resultou no aumento da eficiência na proteção contra danos ao acrossoma espermático durante o processo de criopreservação. Dessa forma, a associação desses antioxidantes potencializa de forma eficiente, a conservação das características de membrana plasmática e acrossomal após o processo de criopreservação.

A avaliação da atividade mitocondrial é utilizada como uma ferramenta para medir a função mitocondrial e a sua relação com a síntese de ATP. As mitocôndrias são a principal fonte de produção dos radicais livres dentro da célula (Boveris 1976, Schapira 1998). Observamos que a adição da associação dos antioxidantes melhorou a função mitocondrial, principalmente quando havia a presença da melatonina. A elevada atividade mitocondrial observada nas associações com a presença da melatonina exerce uma atuação direta nas mitocondrias, contra a o estresse oxidativo.

Como a melatonina é uma molécula anfifílica, ela é capaz de atravessar as membranas celulares com facilidade e, assim, atingir compartimentos subcelulares, podendo acumular-se em concentrações elevadas nas organelas, como a mitocôndria (Venegas et al. 2012). Assim, a melatonina elimina os radicais livres gerados na mitocôndria, reduz a perda de elétrons na cadeia respiratória, e reduz a formação de EROs (Leon et al. 2004).

A melatonina, além de ser capaz de proteger as mitocôndrias dos danos oxidativos, reduzindo o consumo de oxigênio, é capaz de melhorar o potencial da membrana e a produção do ânion superóxido, mantendo, ao mesmo tempo, a produção de ATP (Lopez et al. 2009). Assim, a ação da melatonina tem duas consequências para esta organela: causa uma estimulação cíclica na atividade da GPx e GRx e regenera o GSH para ser usado em outros processos antioxidantes pela mitocôndria, e/ou melhora a função mitocondrial desintoxicando hidroperóxidos (Martín et al.

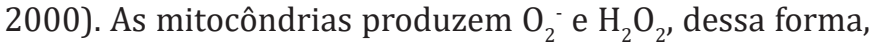
elas devem ser desintoxicadas, através GSH, para evitar a elevada produção de -OH (Martín et al. 2000).

A alta atividade mitocondrial ocorreu quando da adição da associação melatonina com ácido ascórbico e Trolox C, provavelmente a estabilidade de cada antioxidante, por meio de suas características individuais, quando incorporadas à célula espermática, em especial, nas mitocôndrias. Além do que, a melatonina nessa organela, atua diretamente contra os radicais livres que reduzem a produção de ATP, bem como as estruturas flagelares, consequentemente, reduz a geração de EROs, preservando e mantendo a função mitocondrial durante a variação de temperatura que os espermatozoides passam no processo de congelação e descongelação.

0 teste in vitro de ligação dos espermatozoides à membrana perivitelina da gema de ovo de galinha auxilia a predizer o potencial fecundante dos espermatozoides, além de ser relativamente simples e de fácil execução (Graham \& Moce 2005, Moraes et al. 2010). Assim, conforme observado neste estudo, à associação dos três antioxidantes aumentou o número de espermatozoides ligados, devido 
a melhor preservação de suas funções após o processo de criopreservação.

No que se refere a geração de EROs, a produção de MDA vem sendo utilizada como indicador de estresse oxidativo em vários tipos de células (Sikka 1996), incluindo as espermáticas (Souza et al. 2016). Os espermatozoides são muito sensíveis aos efeitos da peroxidação, e a sua capacidade fecundante é prejudicada devido à apoptose e aos danos no DNA (Martinez-Pastor et al. 2009). Com base nos resultados, a concentração de MDA não apresentou redução, entretanto, demostrou que a adição de antioxidantes auxilia de alguma forma a redução dos danos oxidativos gerados durante a criopreservação dos espermatozoides.

Conforme a qualidade espermática observada após análise dos diferentes parâmetros, realizadas nesse estudo, sugere-se que a ausência de efeito antioxidante após a quantificação no número de espécies reativas ao ácido tiobarbitúrico, demonstra que o estresse oxidativo não influenciou na qualidade dos espermatozoides criopreservados, visto que as diferentes associações de antioxidante, em especial a associação MEL+AA+TRO, foram eficientes em melhorar a qualidade e o potencial fecundante dos espermatozoides.

Outro aspecto importante a ser levado em consideração, visando evitar os efeitos deletérios das EROs, é à dose utilizada, quantidades insuficientes ou elevadas de antioxidante em uma adição, não apresentariam os efeitos desejados. Apesar do sêmen diluído, ter recebido uma adição com antioxidantes associados, à atividade desses, não atingiu o nível necessário de proteção, capaz de promover a redução da concentração de MDA. Assim, tratamentos com diferentes concentrações e associações de antioxidantes visando identificar a concentração ideal, é imprescindível.

Os dados apresentados neste estudo mostraram resultados positivos quanto à adição de antioxidantes associados no sêmen diluído, visando promover melhoria da qualidade espermática, comprovando, através dos testes laboratoriais in vitro, o aumento da motilidade, a preservação da integridade das membranas plasmática e acrossomal, o aumento da atividade mitocondrial e a capacidade dos espermatozoides de se ligarem à MPV, consequentemente, melhorando o potencial fertilizante de espermatozoides descongelados de carneiros. Possibilitando assim, quando da adição desses antioxidantes nos protocolos de criopreservação de sêmen ovino, a utilização de um material genético com melhor qualidade pós descongelação, buscando elevar os índices de fecundidade do rebanho.

Vale ressaltar que os resultados desse estudo mostraram que a concentração dos antioxidantes utilizada é de importância crucial para obter o efeito protetor desejado. Em termos gerais, os resultados obtidos mostram que a adição da associação MEL+AA+TRO no diluente para criopreservação, favoreceu a redução do efeito deletério ocasionado pela crioinjúria na célula espermática, durante os procedimentos de congelação/descongelação. Por outro lado, novos estudos devem ser realizados para identificar a melhor concentração de cada antioxidante nessa associação.

\section{CONCLUSÃO}

A adição da associação dos antioxidantes (melatonina, ácido ascórbico e Trolox C) no sêmen diluído de carneiros antes da criopreservação melhora a qualidade espermática e, os protege das crioinjúrias, melhorando o potencial fecundante in vitro após a criopreservação, podendo ser adicionados em protocolos de criopreservação de sêmen ovino.

Agradecimentos.- A CAPES, pela bolsa de estudo. Ao Centro de Pesquisa em Suínos, Espécies Nativas e Silvestre (CPSENS) do CPGCA/UNIVASF por toda infraestrutura (APQ-1072-5.04/12 e APQ-0227-5.04/10) e suporte para a realização da pesquisa. A Pró Reitoria de Pesquisa e Pós-Graduação da UNIVASF pelo suporte financeiro para aquisição de equipamentos (Projeto financiado em Edital 17/2013).

\section{REFERÊNCIAS}

Albertini R. \& Abuja P.M. 1999. Prooxidant and antioxidant proprieties of Trolox C, analogue of vitamin E, in oxidation of low-density lipoprotein. Free Radic. Res. 30(3):181-188.

Ashrafi I., Kohram H. \& Ardabili F.F. 2013. Antioxidative effects of melatonin on kinetics, microscopic and oxidative parameters of cryopreserved bull spermatozoa. Anim. Reprod. Sci. 139(1/4):25-30.

Barreiros A.L.B.S., David J.M. \& David J.P. 2006. Estresse oxidativo: relação entre geração de espécies reativas e defesa do organismo. Quím. Nova 29(1):113-123.

Baumber J., Vo A., Sabeur K. \& Ball B.A. 2002. Generation of reactive oxygen species by equine neutrophils and their effect on motility of equine spermatozoa. Theriogenology 57:1025-1033.

Bielski B.H., Richter H.W. \& Chan P.C. 1975. Some properties of the ascorbate free radical. Ann. N.Y. Acad. Sci. 258(1):231-237.

Bilodeau J.F., Blanchette S., Cormier N. \& Sirad M.A. 2002. Reactive oxygen species-mediated loss of bovine sperm motility in egg yolk Tris extender: protection by pyruvate, metal chelators and bovine liver or oviductal fluid catalase. Theriogenology 57:1105-1122.

Boveris A. 1976. Mitochondrial production of superoxide radical and hydrogen peroxide. Adv. Exp. Med. Biol. 78:67-82.

Bucak M., Ateșşahin A., Varișli O., Yüce A., Tekin N. \& Akçay A. 2007. The influence of trehalose, taurine, cysteamine and hyaluronan on ram semen: Microscopic and oxidative stress parameters after freeze-thawing process. Theriogenology 67(5):1060-1067.

Bucak M.N., Atessahin A. \& Yüce A. 2008. Effect of anti-oxidants and oxidative stress parameters on ram semen after the freeze-thawing process. Small Rumin. Res. 75:128-134.

Casey P.J., Hillman R.B., Robertson K.R., Yudin A.I., Liu I.K.M. \& Drobins E.Z. 1993. Validation of an acrosomal stain for equine sperm that differentiates between living and dead sperm. J. Androl. 14(4):289-297.

Castilho F.E., Guimarães D.J., Martins F.L., Pinho O.R., Guimaranhães F.E.S. \& Espeschit B.J.C. 2009. Uso de própolis e ácido ascórbico na criopreservação do sêmen caprino. Revta Bras. Zootec. 38(12):2335-2345.

CBRA 2013. Manual para Exame Andrológico e Avaliação de Sêmen Animal. $3^{a}$ ed. Colégio Brasileiro de Reprodução Animal, Belo Horizonte. 104p.

Chatterjee S. \& Gagnon C. 2001. Production of reactive oxygen species by spermatozoa undergoing cooling, freezing and thawing. Mol. Reprod. Dev. 59:452-458.

Costa J.M.S., Souza W.L., Moraes E.A., Torres L.R.C., Lima D.I.B., Coelho V.G. \& Sousa P.H.F. 2016. Effect of Trolox C and ascorbic acid on the binding capacity of sperm ram after cryopreservation. 42nd Annual Conference of the IETS, Louisville, KY. Reprod. Fert. Dev. 28:154-155.

Da Silva Maia M., Bicudo S.D., Azevedo H.C., Sicherle C.C., Sousa D.B. \& Rodello L. 2009. Motility and viability of ram sperm cryopreserved in a Tri-egg yolk extender supplemented with anti-oxidants. Small Rumin. Res. 85:85-90.

Drevet J.R. 2006. The antioxidant glutathione peroxidase family and spermatozoa: a complex story. Mol. Cell Endocrinol. 250(1/2):70-79. 
Gomez E., Irvine D.S. \& Aitken R.J. 1998. Evaluation of a spectrophotometric assay for the measurement of malondialdehyde and 4- hydroxyalkenals in human spermatozoa: relationships with semen quality and sperm function. Int. J. Androl. 21(2):81-94.

Graham J.K., Foote R.H. \& Parrish J.J. 1986. Effect of dilauroyphosphatidylcholine on the acrosome reaction and subsequent penetration of bull sperm into zona-free hamster eggs. Biol. Reprod. 35(2):413-424.

Graham J.K., Kunze E. \& Hammerstedt R.H. 1990. Analysis of sperm cell viability, acrosomal integrity, and mitochondrial function using flow cytomitry. Biol. Reprod. 43(1):55-64.

Graham J.K. \& Mocé E. 2005. Fertility evaluation of frozen/thawed semen. Theriogenology 64(3):492-504.

Hardeland R., Tan D.X. \& Reiter R.J. 2009. Kynuramines, metabolites of melatonin and other indoles: The resurrection of an almost forgotten class of biogenic amines. J. Pineal Res. 47(2):109-126.

Kasimanickam R., Pelzer K.D., Kasimanickam V., Swecker W.S. \& Thatcher C.D. 2006. Association of classical semen parameters, sperm DNA fragmentation index, lipid peroxidation and antioxidant enzymatic activity of semen in ram-lambs. Theriogenology 65:1407-1421.

Keshtgar S., Iravanpour F., Gharesi-Fard B. \& Kazerooni M. 2016. Combined effect of Trolox and EDTA on frozen-thawed sperm quality. Iran J. Med. Sci. 41(3):230-237.

Khalil W.A., Marei W.F. \& Khalid M. 2013. Protective effects of antioxidants on linoleic acid-treated bovine oocytes during maturation and subsequent embryo development. Theriogenology 80(2):161-168.

Krzyzosiak J., Evenson D., Pitt C., Jost L., Molan P. \& Vishwanath R. 2000. Changes in susceptibility of bovine sperm to in situ DNA denaturation, during prolonged incubation at ambient temperature under conditions of exposure to reactive oxygen species and nuclease inhibitor. Reprod. Fertil. Dev. 12:251-261.

Lei X.Y., Zhu R.Y., Zhang G.Y. \& Dai Y.R. 2004. Attenuation of cold-induced apoptosis by exogenous melatonin in carrot suspension cells: the possible involvement of polyamines. J. Pineal Res. 36(2):126-131.

Leon J., Acuña-Castroviejo D., Sainz R.M., Mayo J.C., Tan D.X. \& Reiter R.J. 2004. Melatonin and mitochondrial function. Life Sci. 75(7):765-790.

Li P., Li Z.-H., Dzyuba B., Hulak M., Rodina M. \& Linhart O. 2010. Evaluating the impacts of osmotic and oxidative stress on common carp (Cyprinus carpio, L.) sperm caused by cryopreservation techniques. Biol. Reprod. 83:852-858.

Lopez A., García J.A., Escames G., Venegas C., Ortiz F., López L.C. \& AcuñaCastroviejo D. 2009. Melatonin protects the mitochondria from oxidative damage reducing oxygen consumption, membrane potential, and superoxide anion production. J. Pineal Res. 46(2):188-198.

Maia M.S., Bicudo S.D., Azevedo H.C., Sicherle C.C., Sousa D.B. \& Rodello L. 2009. Motility and viability of ram sperm cryopreserved in a Tris-egg yolk extender supplemented with anti-oxidants. Small Ruminant Res. 85(2):85-90.

Martinez-Pastor F., Aisen E., Fernández-Santos M.R., Esteso M.C., Maroto-Morales A., García-Álvez O. \& Garde J.J. 2009. Reactive oxygen species generators affect quality parameters and apophysis markers differently in red deer spermatozoa. Reproduction 137(2):225-235.

Martín M., Macías M., Escames G., León J. \& Acuña-Castroviejo D. 2000. Melatonin but not vitamins $\mathrm{C}$ and $\mathrm{E}$ maintains glutathione homeostasis in t-butyl hydroperoxide-induced mitochondrial oxidative stress. FASEB J. 14(12):1677-1679.

Mies Filho A. 1987. Inseminacao artificial. Vol.2. Sulina, Porto Alegre. 701p.

Miki K. 2007. Energy metabolism and sperm function. Soc. Reprod. Fertil. 65(Suppl.):309-325.

Moraes E.A., Graham J.K., Torres C.A.A., Meyers M. \& Spizziri B. 2010. Delivering cholesterol or cholestanol to bull sperm membranes improves cryosurvival. Anim. Reprod. Sci. 118(2/4):148-154.

NRC 2007. Nutrient Requirements of Small Ruminants: sheep, goats, cer- vids, and New World camelids. National Requirement Council, National Academy of Science, Washintgton, D.C. 347p.

Neuzil J., Thomas S.R. \& Stocker R. 1997. Requirement for, promotion, or inhibition by alpha-tocopherol of radical-induced initiation of plasma lipoprotein lipid peroxidation. Free Radic. Biol. Med. 22(1/2):57-71.

Ohkawa H., Ohishi N. \& Yagi K. 1979. Assay for lipid peroxides in animal tissues by thiobarbituric acid reaction. Anal. Biochem. 95(2):351358.

Peel M.C., Finlayson B.L. \& McMahon T.A. 2007. Updated world map of the Köppen-Geiger climate classification. Hydrol. Earth Syst. Sci. 11:16331644.

Pereira C., Agostinho P., Moreira P.I., Duarte A.I., Santos M.S. \& Oliveira C.R. 2003. Estratégia de neuroproteção: Efeito da vimpocetina em modelos in vitro de stress oxidativo. Acta Med. Port. 16:401-406.

Peyrot F. \& Ducrocq C. 2008. Potential role of tryptophan derivatives in stress responses characterized by the generation of reactive oxygen and nitrogen species. J. Pineal Res. 45(3):235-246.

Reiter R.J., Tan D.X., Osuna C. \& Gitto E. 2000. Actions of melatonin in the reduction of oxidative stress: a review. J. Biomed. Sci. 7(6):444-458.

Reiter R.J., Tan D.X. \& Terron M.P. 2007. Melatonin and its metabolites: new findings regarding their production and their radical scavenging actions. Acta Biochim. Pol. 54(1):1-9.

Ross L., Barclay C., Artz J.D. \& Mowat J.J. 1995. Partitioning and anti-oxidant action of the water-soluble antioxidant, Trolox, between the aqueous and lipid phases of phosphatidylcholine membranes: $\mathrm{C}$ tracer and product studies. Biochem. Biophys. Acta. 1237(1):77-85.

Santos M.A.M., Gradela A., Moraes E.A., Souza W.L., Alves N.G., Costa J.M.S. \& Matos W.C.G. 2015. Características do sêmen a fresco e descongelado de garanhões da raça Nordestina. Pesq. Vet. Bras. 35(11):925-932.

Sariozkan S., Bucak M.N., Tuncer P.B., Taşdemir U., Kinet H. \& Ulutaş P.A. 2010. Effects of different extenders and centrifugation/washingon postthaw microscopic-oxidative stress parameters and fertilizing ability of Angora buck sperm. Theriogenology 73(3):316-323.

Sarlós P., Molnar A., Kokai M., Gabor G.Y. \& Rátky J. 2002. Comparative evaluation of the effect of anti-oxidants in the conservation of ram semen. Acta Vet. Hung. 50:235-245.

SAS 2002-2008. SAS System for Windows (Statistical Analysis System), versão 9.2. SAS Institute Inc., Cary, USA.

Schapira A.H.V. 1998. Mitochondrial dysfunction in neurodegenerative disorders. Biochim. Biophys. Acta 1366(1/2):225-233.

Sikka S.C. 1996. Oxidative stress and role of antioxidants in normal and abnormal sperm function. Front. Biosci. 1:78-86.

Silva P.F.N. 2006. Physiology of peroxidation process in mammalian sperm. Doctoral Thesis, Utrecht University, Faculty of Veterinary Science, Utrecht University, Utrecht. 177p.

Sharma R.K. \& Agarwal A. 1996. Role of reactive oxygen species in male infertility. Urology 48(6):835-850.

Souza W.L., Lima D.I.B., Moraes E.A., Costa J.M.S., Torres L.R.C., Coelho V.G. \& Magalhaes L.M.V. 2015. Adição de diferentes concentrações de crioprotetores e gema de ovo sobre a motilidade espermática progressiva de ovinos após a criopreservação. Anais XXV Congresso Brasileiro de Zootecnia 25:1-3.

Souza W.L., Moraes E.A., Costa J.M.S., Sousa P.H.F., Lopes Junior E.S., Oliveira R.P. \& Toniolli R. 2016. Efeito de diferentes concentrações de melatonina em espermatozoides de carneiros sobre estresse oxidativo após criopreservação. Pesq. Vet. Bras. 36(7):657-664.

Taylor C.T. 2001. Antioxidants and reactive oxygen species in human fertility. Environ. Toxicol. Pharmacol. 10(4):189-198.

Venegas C., García J.A., Escames G., Ortiz F., López A., Doerrier C., García-Corzo L., López L.C., Reiter R.J. \& Acuña-Castroviejo D. 2012. Extrapineal melatonin: analysis of its subcellular distribution and daily fluctuations. J. Pineal Res. 52(2):217-227. 